\title{
EXAMINING RESEARCH SPACES IN DOCTORAL PROSPECTUSES
}

\author{
Yazid Basthomi \\ Universitas Negeri Malang, Indonesia
}

\begin{abstract}
Genre analyses and contrastive rhetoric studies have dealt with quite a number of genres of writing. However, genre analysts and contrastive rhetoric researchers have not carried out adequate analyses of doctoral prospectuses. This paper will, subsequently, address this issue by analyzing a genre of texts of doctoral prospectuses. The analysis will be focused on the sub-genre of "Background of the Study" of the prospectuses. Limitations of accessibility, however, have led this study to only focus on analyzing fourteen doctoral prospectuses written in English by Indonesian students of EFL accessible from the Graduate Program, State University of Malang, Indonesia. This situation suggests that the present study is preliminary. Preliminary, notwithstanding, the study will contribute to filling the gap of the underresearched issue of doctoral studies in Indonesia, particularly, those pertinent to the area of ELT. The analysis shows a tendency that the texts of Background of the Study do not show research spaces. Relevant to this, the article provides an interpretive explanation of the possible factors attributable to this issue.
\end{abstract}

Key words: EFL, ELT, doctoral prospectuses, research space

Some research projects have been devoted to addressing the issues of doctoral studies (e.g., Barnes, 2005; Bingman, 2003; Cox-Peterson, 2004; Falkner, 2001; Mehra, 2004; Pullen, 2003; Hsing-I, 2004; Scott, 2000; Swales, 2004). However, all of the sample literature deals with doctoral studies in the U.S. with an exception of that of Swales (2004). Swales' treatment of the U.S. Ph.D. defense is put against the backdrop of a synoptic presentation of his anecdotal observations of some doctoral defenses in academic venues outside the U.S., particularly, those in Europe. Even so, his main focus is on the Ph.D. defense in 
the U.S. In addition, he has not provided adequate examination of doctoral research proposals or prospectuses (Swales, 2004).

A similar situation holds true in the Indonesian context of graduate studies. To the best of my knowledge, no project has been dedicated to analyzing doctoral prospectuses of Indonesian students of EFL. In the Indonesian setting, I am aware of Rohmah's (2006) project which, with some degree of detail, has dealt with Indonesian doctoral students of EFL. Yet, unfortunately, along with the absence of research on doctoral studies in Indonesia, Rohmah's has been limited to the investigation of doctoral students' strategies in expressing disagreement within the confines of classroom discursive practice. So, despite its insightful illumination, Rohmah's has nothing to offer vis-à-vis the practice of writing doctoral prospectuses in the Indonesian context of EFL teaching and learning.

Pertinent to TEFL enterprise, particularly the writing performance of EFL students and nonnative speakers of English, the advent of Kaplan's seminal work on contrastive rhetoric in the 1960s (Kaplan, 1966, 1980) has stimulated a number of other studies on various genres of writing, such as letter writing, academic writing, newspaper articles, research articles, and research proposals (e.g., Cahyono, 2007; Fakhri, 2004; Mirahayuni, 2002; Adnan, 2004, Susilo, 2004; Basthomi, 2006, 2008). However, as mildly noted earlier, contrastive rhetoric studies on doctoral prospectuses have been neglected. The fact that there have been quite a number of studies addressing the issues of graduate studies as noted above has not provided necessary documentation about the performance of Indonesian EFL doctoral students in attempting to show research spaces in their doctoral prospectuses. Accordingly, an aspect of ELT in the Asian setting has not been adequately explicated.

In my view, the writing of doctoral prospectus requires the writer showing a "research space" similar to that in the writing of research articles (RAs) as has been advocated by Swales (1990, 2004). Ability to show a research space demonstrates that a researcher is knowledgeable, not necessarily erudite, about what has been going on in the given area s/he is trying to delve into. However, as a comparison, in my own recent project (Basthomi, 2006), I found that Indonesians writing research articles in English tend to be weak at attempts to show a research niche, attesting the findings of Safnil (2000) and Mirahayuni (2001, 2002). Taking this notion into account, I would hypothesize that Indonesian students of EFL tend to be weak at showing a research space in their doctoral prospectuses. This hypothetical notion, however, is far from being 
conclusive. This paper will, therefore, address this issue by analyzing texts of doctoral prospectuses written in English by Indonesian students of EFL.

Due to problems of accessibility, this study will be focused on analyzing doctoral prospectuses accessible from the Graduate Program, State University of Malang, Indonesia. The present study is, therefore, preliminary in nature. Despite its nascent exegesis, the study will contribute to the initiation of research endeavors pertaining to doctoral studies in the area of ELT in Indonesia. As well, concern about the notion of "research space" will mean extension of application of Swales' Create a Research Space model (1990; 2004) to another genre of writing. So, germane to the foregoing discussion, the problem in the present research project can be spelled as follows: "How do Indonesian doctoral students of EFL work about research spaces in their doctoral prospectuses?" To answer this problem, the analysis of the texts of doctoral prospectuses will be carried out, as mildly noted above, in the light of Swales' CARS Model.

\section{METHOD}

To answer the abovementioned question, this section sketches information about the corpus to analyze in this project. The sources of the data to collect were doctoral prospectuses written in English by doctoral students majoring in English Language Education at the Graduate Program, State University of Malang, Indonesia.

In collecting the data, I firstly considered the point of data redundancy. Referring to my experience of analyzing research articles (RAs) written in English by Indonesians (Basthomi 2006), I learned that redundancy started to emerge as I analyzed some ten articles. I used this information as my starting point. However, due to some limitations, I failed to randomly select the sample from the intended number of doctoral prospectuses. Consequently, I also failed to commit to the idea of data redundancy.

So, in the selection of the doctoral prospectuses as the sources of the data, I conceded to employ a purposive-convenient sampling (Ary et al., 2002; Fraenkel and Wallen, 2003; Seidman, 1991); I could only avail myself (most of which through my attendance to the qualifying exams for candidature) of fourteen doctoral prospectuses (see Appendix 1). 


\section{FINDINGS AND DISCUSSION}

This section will present two points of results of my reading of the fourteen doctoral prospectuses, particularly, the subheading of "Background of the Study", and some points of interpretive explanation or discussion of the two points of findings.

\section{Findings}

My reading of the subheading of "Background of the Study" of the prospectuses has led me to a tentative conclusion that it serves as the core of Chapter I. In terms of the length, the fourteen doctoral prospectuses analyzed can be classified into three categories: short, medium, and long. The short texts run on about 8 paragraphs, the medium about 20 paragraphs, and the long over 30 , yet less than 40 paragraphs. So, with regard to the length of the background texts, there seems to be a relatively big variability. Irrespective of the length, there is a strong tendency that the texts of Background of the Study are crowded with review of concepts.

\section{The Salient Problem of "Review of Concepts"}

As we cast our attention onto the sample analysis of the background text of a proposal titled "Genre Analysis of International Conference Paper Abstracts" which hosts 34 paragraphs, we find that out of the 34 paragraphs, 21 paragraphs relate to review of concepts. Indeed, Swales' (1990) model makes a mention on a "review" of something; yet, Swales (1990) specifies it to the "review of items of previous research." This means that Swales stipulates that in the attempt to "establish a territory" thus working on a research space, a writer is required to relate his/her research to the "web" of studies in the given area of research conducted.

To discuss this matter a little further, I would refer to the basic formulation of academic advancement. In a simple (metaphorical) formulation, academic endeavor (research) can be deemed to be attempts to add a "second story" to the "first story" of the existing academic discourse. Research proposal is the means by which the doctoral candidate shows the significance why she or he proposes to conduct the project, significance in the sense of offering a "second story" to the established academic discourse or the "first story."

Germane to this discussion is Swales' $(1990 ; 2004)$ formulation of Create a Research Space or CARS model of research articles. Stipulated in the model is that a researcher, particularly in developed countries, is compelled to show, 
in order to convince the audience, that she or he knows what is going on in the scholarly discourse (first story) within her or his topic of the proposed research. By the same token, back to the case of the doctoral candidature, the prima facie the doctoral candidate has to deal with is to convince the examiners, as part of their audience, that she or he knows the "first story" and knows how to add it with a "second story", that is, the one she or he is proposing.

The above point is what constitutes the significance of her or his proposed project. In this case, review of related literature is critical, for the review is the aspect which allows the candidate to know the "first story" so that the "second story" she or he is working on or proposing relevantly links to the "first story". In this regard, I believe, the best way to know the "first story" is to review previous studies (the empirical points) instead of review of concepts, for I believe, the doctoral proposals analyzed in this research are empirical research projects. The situation is probably quite different from research projects in the area of, for instance, philosophy in which the researchers deal, to a great extent, with concepts.

So, since research proposals in the area of English Language Education which are analyzed in this present research are empirical research, review of concepts in the Background of the Study does not really help the writer show that she or he is really familiar with the "first story" and then able to put forth a "second story." The corollary is that labor on review of concepts does not really show the researchers' critical points which show that the research being proposed is really significant to conduct. In what follows, we shall discuss further the point of "criticality."

\section{Problem of Critiquing}

My reading of the backgrounds of the fourteen abovementioned doctoral prospectuses has also given me the impression that the writers tend not to be really successful in working about the research space. The failure mainly relates to the idea that the writers do not really "problematize" the proposed topic at issue. Since all of the proposed topics in the fourteen prospectuses implicate empirical (v.s. conceptual) findings requiring the researchers to conduct field data collection, I assume that, in the background, the writers would present their critical review or problematization of the existing/previous empirical research findings related to the topic being raised. It is true that all of the backgrounds present some review of the literature. However, the review tends to be of conceptual propositions. The literature reviewed in the background does not 
indicate that it relates to empirical findings closely relevant to the topic under investigation; the review tends to provide discussion (or, sometimes, elaboration) of concepts. Referring to Swales (2004), the backgrounds lack "negative justification' for the proposed research; the backgrounds do not provide negative evaluation of the previous empirical research findings. Excerpt 1 epitomizes a typical review of previous studies (retyped verbatim from a prospectus titled Genre Analysis of International Conference Paper Abstracts, page 3).

\section{Excerpt 1}

Genre studies have been conducted by linguists and other professionals in various speech communities and various settings. By various speech communities, it is meant that genre analysis is done on the subject of different groups of people who form a community (Richards et al., 1993). By various settings it is meant that genre analysis is also done in relation to other disciplines, such as technology, politics, mass media, literature, and applied linguistics. Thus, in order to understand a genre analysis, studies on genres related to various speech communities and settings should be taken into account.

For the applied linguists, a genre-based approach to the study of spoken and written texts has the potential to offer a highly relevant medium for seeking a clear level of linguistic knowledge or identifying a clear level of skills as targets for language learning the syllabus design (McCarthy 2001:116). This is because the results of genre analysis can be considered a good guide for the linguists to identify the linguistic repertoire and the social action depicted in such a genre. Due to such promising results of genre analysis, this research attempts to focus on the genre analysis on international conference paper abstracts. By analyzing these abstracts, a certain pattern such as the move, textual metadiscourse and linguistic realization can be clearly identified. Such a pattern will contribute to the writers who want to write an abstract for the international conference papers in an international conference of certain speech community.

The excerpt indicates nothing about critique or negative evaluation of the proposition by the ones the writer is referring to; $s /$ he is not leveling critique at Richards et al.'s and McCarthy's ideas. In fact, the last three sentences of the second paragraph indicate what Samraj (2002) as quoted in Swales (2004:230) refers to as 'presenting positive justification'. 
With the above point, I am not saying that positive justification is unnecessary. What I am indicating, rather, is that positive justification alone does not really provide adequate information about the researcher's understanding of the given topic. It does not show that the researcher has critically reviewed enough of the necessary materials of the existing literature, which shows that $\mathrm{s} / \mathrm{he}$ has been successful to arrive at the core problem significant to research on. Instead of exhausting her/his energy to critically review and/or problematize relevant empirical research findings around the issue at stake, the writer tends to spend her/his energy presenting or elaborating concepts (or definitions of concepts) pertinent to her/his research variable(s). Excerpt 2 exemplifies the typical conceptual review residing in the doctoral prospectus backgrounds (retyped word for word from a proposal titled Learning Strategies across Cultures of EFL Learners Residing in Nusa Tenggara Timur (NTT) Province, page 3).

\section{Excerpt 2}

Up to this point, knowing more of what learning strategies are all about is important. Learning strategies refer to any specific procedures, ways, techniques or tactics learners use in learning a language, especially in learning English. It is believed that every EFL learner adopts specific learning strategies. Every EFL learner can use different learning strategies showing his or her way of learning. For example, an EFL learner, in making meaning of an unfamiliar word in an English reading passage, may adopt consulting dictionary strategy and another may use inferring from context strategy.

The writer seems, as indicated in Excerpt 2, to be cognizant of the main variable of her/his proposed research. However, this knowledge seems to have directed her/him to feeling the need to present concepts around the variable, that is, strategies, instead of problematizing issues about the variable on the basis of the existing empirical research findings.

If we compare this situation with Swales' (2004) conception of "establishing a niche" which constitutes the idea of carving out "a research space" in his CARS model, the Indonesian doctoral writers tend to opt for "positive justification", putting aside the other two steps of "indicating a gap", and "adding to what is known". We should also note that "positive justification" in Swales (2004) CARS is optional. So, the Indonesian writers of doctoral prospectuses tend to focus on "positive justification". This is similar to Indonesian writers of research articles (RAs) as reported and reflected in Safnil's (2000) "Project 
Justifying Problem Model" (we will revert to this point later in this section). Native speakers of English, on the other hand, as reflected in Swales' (2004) model, tend to focus on "indicating a gap" and "adding to what is known" which are done by reviewing relevant literature (but not necessarily excessively reviewing and providing definitions of concepts, irrespective of their close relationship with the research variables).

\section{Discussion: Winnowing the Grain}

The foregoing presentation of findings has been about the salient features of the backgrounds of doctoral prospectuses written in English by some Indonesian students of EFL: the surfacing failure in showing a research space in the background warrants further discussion, particularly, pertaining to the possible reasons for the failure.

In the background, the writers usually talk about the variable(s) of the proposed research by presenting definitions of particular concepts or by discussing conceptual issues relating to the research variable(s). The backgrounds also usually sketch justifying reasons for conducting the proposed research project. They usually do not, however, provide discussion of the research variable(s) by critically reviewing or problematizing the existing empirical research findings of relevant issues. In addition, the writers do not usually provide information to what extent the proposed research is similar to and/or different from the previous research projects. The writers lack attempts to indicate the position of the proposed research project within the web of the existing relevant research projects. This being the case, the tendency is that the proposed research projects seem to emerge arbitrarily-devoid of firmed connection with other research projects. A pertinent question would be as to why this all happens.

In response to the above question, I would think that positive justification is culturally easier for Indonesians. It does not necessarily require the writer to explicitly critique or oppose or counter previous researchers; thus, it reduces the risk of face-threatening act (Ahmad, 1997). Perhaps Adnan (2004) puts it right that such a phenomenon is due to the academic situation in Indonesia; Indonesian academic life is still in its young age.

Mildly noted earlier, critical evaluation of the existing literature by other writers has to do with citing behaviors (in reviewing pertinent literature). In the case of Indonesian academic milieu, Adnan (2004) reports on insightful findings. One of the important findings on which Adnan (2004) reports relates to 
the small number of citations in Indonesian academic writings. Another issue on which he touches deals with attitudes of the writers towards the cited works or cited authors. In general, he found that Indonesian RA writers avoid negative attitude towards the works of others. In other words, Indonesian writers tend not to level critiques at others. This seems to be true with the doctoral prospectus writers in the pool of my corpus.

In accounting for such phenomena, Adnan (2004) points to practical and cultural factors. The practical issues deal with lack of resources of which Indonesian academics can avail themselves. This situation is made worse with the fact that the academics have low income. This situation forces them to find other sources of income or moonlighting the consequence of which is that they lose time to search and peruse necessary literature for their academic writings. Apart from the practical issues, culturally, Adnan (2004) goes on, Indonesia is still strongly inclined to orality than literacy (suggesting writing tradition). Adnan points out that this tradition is still tainting the educational system in Indonesia, from the very primary up to the tertiary level.

Another important factor Adnan (2004) identifies is that Indonesian academics are still at a nascent academic culture. Referring to Thomas (1973), he reports that the first tertiary educational institution was established in 1920s. Even so, it was not oriented right from the start to produce academics or researchers. It was set up to fulfill the demand for skilled personnel. Worse still, there were quite few indigenous Indonesians attending the institution. During the Japanese occupation in 1940s, it was even closed. Later on, when it was reoperated, Indonesian government was struggling over financial matters, which are not, I think, resolved more elegantly today. Adnan (2004) further observes that postgraduate programs, which have the potential to be research-oriented, did not exist until 1980s. In other words, research activities which encompass citing behaviors, critiquing, counter-claiming and the like have not been mature enough in the Indonesian academic life.

Despite the illuminating issues Adnan (2004) raises in an attempt to delineate the phenomena, Adnan fails to notice other potential cultural factors. Indonesia might be attributed, to refer to Flowerdew and Miller (1995), with Confucian culture (vis-à-vis Socratic culture of the west). In such a cultural constraint, as Flowerdew and Miller (1995) put it, one is not expected to excel as an individual. Therefore, "critiquing" or more specifically "negative evaluation" which in a sense is a form of self-aggrandizement (which might be felt as "belittling" others) is unlikely to come out. This situation is shared by Tardy's 
(2005) Asian subject who has difficulty "boasting" himself in writing. Accordingly, it is discernible that the backgrounds of the doctoral prospectuses do not really show critical evaluation of other research findings.

We should note that the setting of the corpus is a university in Java. Within such a context, the writers might be bound to Javanese norms to which "unggah-ungguh" is central (Errington, 1988). As an illustration, a Javanese myself, I am still holding an element of the unggah-ungguh which says "ngono yo ngono ning ojo ngono" which has a wide meaning, including the way of critiquing. In terms of leveling a critique, the notion can roughly say: "should you criticize somebody, do not really criticize; find another way-a middle way, perhaps." So, viewed within this frame, critiquing might be measured as too upfront. This being the case, the Indonesian doctoral prospectus writers are likely to avoid critiquing. It does not really emerge in the backgrounds of the doctoral prospectuses; it is underused.

Therefore, it is understandable why my corpus shows "positive justification" in which the writers are not required to explicitly refer to others. Critical review, on the other hand, very likely requires the writers negatively evaluating others. This might be felt by Indonesian doctoral prospectus writers not really desirable within their (academic) culture. This notion seems to have some similarities with that in Malaysia (Ahmad, 1997).

Another point worth highlighting is that, similar to Indonesian English RA writers, Indonesian English doctoral prospectus writers, have a proclivity to dwell on "review of literature on concepts" instead of "review of items or findings of previous empirical research." Since belaboring concepts does not seem to guarantee a success in the attempt to situate the given research in the web of studies in the area, the English doctoral prospectuses by some Indonesian EFL students tend to show a weak preparation for the creation of a research space. This situation is quite similar to RAs in Indonesian (Safnil, 2000) and Malay (Ahmad, 1997).

Safnil (2000:221) has an interesting point, as another comparison, about literature review in Indonesian RAs, that is, it is complicated. He further suggests that literature review in Indonesian RAs has three functions or communicative purposes. The first is "to elaborate the research topic already introduced." The second is "to discuss the current knowledge or practice related to the research topic. The last is "to justify the choice of a particular research method or approach used in the study." The first point particularly shares a common notion with what I mean by "review of literature on concepts" or 
"elaborating concepts." This deals with giving definitions or explanation of certain issues pertinent to the research topic. As to why this happens might also be delineated in the same way as the above issue of "critiquing" which relates to citing behaviors. Indonesian academics are still faced with dampening problems of lack of resources and are in a nascent academic culture (Adnan, 2004).

Further, in relation to the "review of literature on concepts" or "elaborating concepts", Mirahayuni (2002) documented three types of reference: reviewing, defining, and affirming. An instance of reviewing type provided by Mirahayuni (2002: 86) is as follows:

These studies show fluctuations of interlanguage development which reflect strategies of learning and overgeneralization .... [...] [emphasis original].

An important point to note here is that this reviewing type deals with review of previous "empirical" studies. As with the defining type, the instance reads as follows:

Language learning strategies can be defined as 'the mental steps or operations that learners use to learn a new language and to regulate their efforts to do so [...] [emphasis original] (Mirahayuni, 2002:88).

This type deals with concepts, which in this article I call "review of literature of concepts." The following instance exemplifies the last type-affirming type:

Some of those clauses are commitment seeking devices, e.g. "Will you do me a favour," "Could I ask you something?" "I wondered if you could do me a favour," and reinforcing devices which Edmonson (R) calls "supportive moves,"... [emphasis original] (Mirahayuni, 2002:90).

Mirahayuni notes that the first two types are manifest in RAs by both native and non-native English writers, but the last type only appears in RAs by nonnative English speakers. In my corpus, however, I found the defining type is quite frequently employed at the expense of "critical review or problematization of previous research". As with the affirming type, it seems to partly point to the notion of "elaborating concepts" which tends to occupy the backgrounds of doctoral prospectuses by Indonesian students of EFL.

Further comparison with findings of research in the adjacent area, I believe, will be illuminating. Academic writing has never been monolithic (Ahmad, 1997). On such a premise and on the fact that Indonesian academic 
discourse has its own historical situation as noted above, the distinct rhetorical practice of the writing of background of research bears similarity to the characteristics of Safnil's (2000) model of research articles (RAs) written in Indonesian by Indonesian writers. Safnil (2000), who investigated Indonesian RAs by Indonesians found some "deviating" rhetorical manifestation vis-à-vis the CARS model. Or to put it another way, Safnil views the CARS model inadequate to capture the rhetorical performance manifest in Indonesian RAs. Therefore, Safnil puts forward a model intended to capture rhetorical realization in Indonesian RAs.

Safnil calls his model "Problem Justifying Project Model" or PJP model. PJP model consists of four "moves". The first move is "establishing shared schemata." This move is realized by "defining key terms" and/or "referring to the government policy" and/or "giving a short history of the research field" and/or "describing the geographical setting of the research" and/or "making a general claim."

Move 2 is "establishing the research field." Move 2 might be realized by "introducing the actual research topic" and/or "identifying the research problem or phenomena" and "reviewing the current knowledge and practice." Following move 2, move 3 is "justifying the present research project." This undertaking is performed by "indicating inconsistency in previous study results" or "claiming that the topic has never been explored" or "claiming that the topic is necessary to investigate" or "claiming interest in investigating a particular topic."

The last item, move 4 is "announcing the present research." This move might be concretized by "announcing the research purposes" and/or "stating the research questions" and/or "describing the specific features of the research" and/or "stating the expected benefits of the research" and/or "announcing the principal findings" and/or proposing the research hypothesis" and/or "suggesting a solution to the research problem." Table 1 summarizes the PJP model.

The model shows that the notion of "space" or "niche" is not key to Indonesian RAs. This is different from Swales' (1990; 2004) CARS model in which the notion of "space" is central. As such, the writing practice of introductions to research articles in Indonesian by Indonesian writers is similar to the writing of background of study in doctoral prospectuses written in English by Indonesian doctoral students: space tends to be overlooked. 


\section{Table 1. Safnil's (2000) Problem Justifying Project (PJP) Model for Indo- nesian RA Introductions}

\begin{tabular}{ll}
\hline Move 1 & Establishing Shared Schemata by: \\
& Step A: Defining key terms; and/or \\
& Step B: Referring to the government policy; and/or \\
& Step C: Giving a short history of the research field; and/or \\
& Step D: Describing the geographical setting of the research; and/or \\
& Step E: Making a general claim. \\
Move 2 & Establishing the Research Field by: \\
& Step A: Introducing the actual research topic; and/or \\
& Step B: Identifying the research problem or phenomena; and \\
Move 3 & Step C: Reviewing the current knowledge and practice. \\
& Justifying the Present Research Project by: \\
& Step A: Indicating inconsistency in previous study results; or \\
& Step B: Claiming that the topic has never been explored; or \\
& Step C: Claiming that the topic is necessary to investigate; or \\
Move 4 & Step D: Claiming interest in investigating a particular topic. \\
& Announcing the Present Research by: \\
& Step A: Announcing the research purposes; and/or \\
& Step B: Stating the research questions; and/or \\
& Step C: Describing the specific features of the research; and/or \\
& Step D: Stating the expected benefits of the research; and/or \\
& Step E: Announcing the principal findings; and/or \\
& Step F: Proposing the research hypothesis; and/or \\
Step G: Suggesting a solution to the research problem.
\end{tabular}

\section{CONCLUDING REMARKS}

Some summarizing points of our discussion thus far and expectations for the future can be presented as follows.

\section{Summary (and a little beyond)}

The present study lies in the realm of English Language Teaching (ELT), specifically, in the Indonesian context. In any circumstances, ELT is set to escort the learners to attain a sound communicative ability (competence). Since the present study has to do with communication, particularly in written form, the issue should be put against the context of communicative competence which encompasses the notion of discourse competence (Savignon, 1997). 
Communicative competence has, since the propagation of Communicative Approach, constituted the paramount goal of ELT (Dobson, 2001).

The writing of doctoral candidacy is unequivocally related to discourse competence which connects to the knowledge and skills to generate either written or spoken texts so as to make them logical in terms of coherence and cohesion. This requires the writer and reader sharing, inter alia, the discourse structure (Savignon, 1997). The discourse structure might include the presentation of information in the backgrounds of doctoral proposals.

Against such a backdrop, the study has documented that Indonesian writers of doctoral prospectuses tend to be frail at the attempts to engrave a research space. Such a phenomenon is evidenced by the fact that they opt for providing, in tandem, positive justification and review or elaboration of concepts, and, on the other hand, avoid critiquing previous research findings. So, it can be construed that the performance of the doctoral prospectus writers presented in the previous discussion has not shown a sound attainment of the discourse competence, especially, with regard to the writing of doctoral prospectuses in English.

\section{Coda: Recommendations}

The findings as summarized above bear some implications one of which is that Indonesian ELT theoreticians and practitioners need to make efforts to help solve the problem; they should mull over ways to sensitize the doctoral prospectus writers of critical points to address in their doctoral proposals so that the research projects are really significant to carry out.

The present project has been limited to fourteen English doctoral prospectuses in the area of ELT. Since other disciplines are likely to have different conventions, some confirmation through more other research is needed so that more comprehensive understanding of the issue can be arrived at. As well, since the performance of the writers under investigation is influenced by those keeping the manifestation of doctoral prospectuses (i.e., thesis supervisors), attempts to work about the performance needs to involve both the writers and the doctoral thesis supervisors. Future research in the area, therefore, needs to incorporate both parties.

The analysis of the data in the present study has been carried out by only one individual. Hence, individual biases might have emerged. Since such a situation might have somehow abated the accuracy of the findings, it is advisable, therefore, that further research be done by employing other individual(s) 
so that a higher degree of validity and reliability of analysis can be attained. To sum up, corroboration of the present research is impending.

\section{REFERENCES}

Adnan, Z. 2004. Citing Behaviours in Indonesian Humanities Research Articles. ASAA E-Journal of Asian Linguistics \& Language Teaching. Issue \#

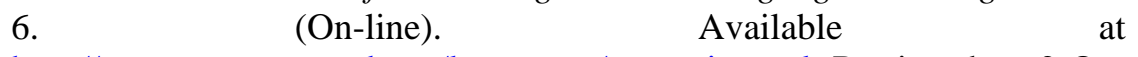
hittp://Www.arts.unsw.edu.au/languages/asaa ejournal. Retrieved on 2 October 2005 .

Ahmad, U. K. 1997. Scientific Research Articles in Malay: A Situated Discourse Analysis. Unpublished Ph.D. Dissertation. Ann Arbor: The University of Michigan.

Ary, D., Jacobs, L. C., and Razavieh, A. 2002. Introduction to Research in Education (6 ${ }^{\text {th }}$ edn.). Belmont, CA: Wadsworth/Thomson Learning.

Barnes, B. J. 2005. Success in Graduate School: How Exemplary Advisors Guide their Advisees. The Michigan State University Ph.D. Dissertation. Ann Arbor: UMI.

Basthomi, Y. 2006. The Rhetoric of Research Article Introductions Written in English by Indonesians. Doctoral Dissertation. Malang: State University of Malang.

Basthomi, Y. 2008. Acknowledging as/Is Respecting: Interlanguage Discourse of Thesis Acknowledgements Section. Paper presented at The 2008 LSP Conference and General Meeting on World Englishes and Second Language Teaching and Learning, the University of Sto. Tomas, Manila, 2830 April 2008.

Bingman, L. G. 2003. African American Doctoral Student Experiences: Factors that Impact Persistence and Graduation. The Michigan State University Ph.D. Dissertation. Ann Arbor: UMI.

Cahyono, B. Y. 2007. A Study of the Quality of Research Grant Proposals in English Education, Linguistics, and Literature. Paper presented at The $5^{\text {th }}$ International Conference on English Language Studies (ICELS 5), Sanata Dharma University, Yogyakarta, Indonesia, 7-8 August, 2007. 
Cox-Peterson, D. L. 2004. A Qualitative Analysis of a Cohort Doctoral Program in Educational Administration. Purdue University Ph.D. Dissertation. Ann Arbor: UMI.

Dobson, A. 2001. Teaching of Culture within Foreign Language Teaching and Its Relationship to Nationalism. Australian Review of Applied Linguistics, 24 (1), 61-73.

Errington, J. 1988. Structure and Style in Javanese: A Semiotic View of Linguistic Etiquette. Philadelphia: University of Pennsylvania Press.

Fakhri, A. 2004. Rhetorical Properties of Arabic Research Article Introductions. Journal of Pragmatics, 36, 1119-1138.

Falkner, T. M. R. 2001. Expansion or Reproduction in Doctoral Education: An Exploration of Doctoral-Program Orientation. The University of Minnesota Ph.D. Thesis. Ann Arbor: UMI.

Flowerdew, J. 2001. Attitudes of Journal Editors to Nonnative Speaker Contributions. TESOL Quarterly, 35 (1), 121-150.

Flowerdew, J. and Miller, L. 1995. On the Notion of Culture in L2 Lectures. TESOL Quarterly, 29 (2), 345-373.

Fraenkel, J. R., and Wallen, N. E. 2003. How to Design and Evaluate Research in Education ( $5^{\text {th }}$ edn.). New York: MacGraw-Hill.

Hsing-I, L. 2004. Learning to Write the Candidacy Examination: Professors and Students Talking about Academic Genres and Authorship. The Ohio State University Ph.D. Dissertation. Ann Arbor: UMI.

Kaplan, R. B. 1966. Cultural Thought Patterns in Intercultural Education. Language Learning. 16, 1-20.

Kaplan, R. B. 1980. Cultural Thought Pattern in Inter-cultural Education. In Keneth Croft (ed.), Readings on English as a Second Language (pp. 399418). Cambridge: Withrop Publishers, Inc.

Mehra, B. 2004. The Cross-cultural Learning Process of International Doctoral Students: A Case Study in Library and Information Science Education. The University of Illinois at Urbana-Champaign Ph.D. Dissertation. Ann Arbor: UMI. 
Mirahayuni, N. K. 2001. Investigating Generic Structure of English Research Articles: Writing Strategy Differences between English and Indonesian Writers. A paper presented at THE $49^{\text {th }}$ TEFLIN International Conference 2001 Kuta, Bali, 6-8 November 2001.

Mirahayuni, N. K. 2002. Investigating Textual Structure in Native and Nonnative English Research Articles: Strategy Differences between English and Indonesian Writers. Ph.D. Thesis. Sydney: The University of New South Wales.

Pullen, F. J. 2003. Perfectionism, Procrastination, and Other Self-reported Barriers to Completing the Doctoral Dissertation. The University of Iowa Ph.D. Thesis. Ann Arbor: UMI.

Rohmah, Z. 2006. Verbal Disagreeing Strategies in Doctoral Classroom Discussions at the State University of Malang. Doctoral Dissertation. Malang: State University of Malang.

Safnil. 2000. Rhetorical Structure Analysis of the Indonesian Research Articles. Unpublished Ph.D. Thesis. Canberra: Australian National University.

Savignon, S. J. 1997. Communicative Competence: Theory and Classroom Practice $\left(2^{\text {nd }} E d n\right.$.).New York: The McGraw-Hill Companies, Inc.

Scott, G. V. 2000. Enculturing an ESL Doctoral Student in Disciplinary Writing: An Apprenticeship Process. Purdue University Ph.D. Thesis. Ann Arbor: UMI.

Seidman, I. E. 1991. Interviewing as Qualitative Research: A Guide for Researchers in Education and the Social Sciences. New York and London: Teachers College, Columbia University.

Susilo. 2004. Thought Patterns as Reflected in the Linguistic Features in Indonesian and English Letters Written by Indonesians. Unpublished Doctoral Dissertation. Malang: PPS UM.

Swales, J. M. 1990. Genre Analysis: English in Academic and Research Settings. Cambridge: Cambridge University Press.

Swales, J. M. 2004. Research Genres: Explorations and Applications. Cambridge: Cambridge University Press. 
Basthomi, Examining Research Spaces 157

Tardy, C. M. 2005. "It's like a story": Rhetorical Knowledge Development in Advanced Academic Literacy. Journal of English for Academic Purposes, 4, 325-338. 


\section{Appendix 1.}

List of the Doctoral Prospectuses Analyzed

\begin{tabular}{|c|c|c|}
\hline No & Title of the Proposed Research* & $\begin{array}{l}\text { Date of Quali- } \\
\text { fying Exam** }\end{array}$ \\
\hline 1. & $\begin{array}{l}\text { Thought Patterns as Reflected in the Linguistic Features in } \\
\text { Indonesian and English Letters Written by Indonesians }\end{array}$ & 2003 \\
\hline 2. & $\begin{array}{l}\text { Portrait of Effective EFL Teachers: A Study on Teachers' } \\
\text { Perspectives }\end{array}$ & 2004 \\
\hline 3. & $\begin{array}{l}\text { Learning Strategies across Cultures of EFL Learners Resid- } \\
\text { ing in Nusa Tenggara Timur (NTT) Province }\end{array}$ & 2004 \\
\hline 4. & $\begin{array}{l}\text { Text Mapping Technique as an Effort to Improve Students' } \\
\text { Reading Comprehension Skill }\end{array}$ & 2004 \\
\hline 5. & $\begin{array}{l}\text { The Impact of the Teaching of English at the Elementary } \\
\text { Schools on the Students' Achievement of English at the First } \\
\text { Year of Lower Secondary School }\end{array}$ & 2004 \\
\hline 6. & $\begin{array}{l}\text { Verbal Disagreeing Strategies in Doctoral Classroom Discus- } \\
\text { sions at the State University of Malang }\end{array}$ & 2005 \\
\hline 7. & $\begin{array}{l}\text { Bilingual Education: A Study on Factors Affecting Students' } \\
\text { Attainment of English Proficiency and Mastery of Subject } \\
\text { Matter }\end{array}$ & 2006 \\
\hline 8. & Acts of Requesting as Realized by EFL Learners & 2006 \\
\hline 9. & $\begin{array}{l}\text { Spoken Error Corrections as Perceived by the EFL Learners } \\
\text { in Speaking Classes }\end{array}$ & 2006 \\
\hline 10. & Teachers' Questions in Reading Comprehension Classes & 2006 \\
\hline 11. & $\begin{array}{l}\text { Profiling Autonomous Learners of the Institut Teknologi } \\
\text { Sepuluh Nopember Surabaya: An Appraisal towards their } \\
\text { Strategies to Learn English }\end{array}$ & 2007 \\
\hline 12. & Genre Analysis of International Conference Paper Abstracts & 2008 \\
\hline 13. & $\begin{array}{l}\text { The Effective Use of English as a Medium of Instruction in } \\
\text { EFL Classes at Senior High School (A Case Study at SMAN } \\
2 \text { Jember) }\end{array}$ & 2008 \\
\hline 14. & $\begin{array}{l}\text { The Learning Experience in EFL Writing of Bilingual Skilled } \\
\text { Writers: A Multi-case Study }\end{array}$ & 2008 \\
\hline
\end{tabular}

* Retyped as they appear in the prospectuses without amendment.

** Some underwent the exam twice. 